\title{
Entusiastas da Cultura: O Universo do Livro e suas Representações nas Cartas do Centro Cultural Euclides da Cunha ${ }^{1}$
}

Culture Enthusiasts: Book Universe and its Representations in the Letters of the Centro Cultural Euclides da Cunha

\author{
Itamar Cardozo LOPES ${ }^{\bullet}$ \\ Cláudio DENIPOTI ${ }^{\bullet}$
}

Resumo: Este artigo é uma breve tentativa de se pensar algumas das muitas ideias e representações construídas no passado sobre o universo do livro. A pesquisa que o originou partiu exclusivamente do exame das correspondências recebidas e acumuladas pelo extinto Centro Cultural Euclides da Cunha, uma agremiação de intelectuais que funcionou de 1948 a 1985 na cidade de Ponta Grossa, no Paraná. Em termos estruturais, o estudo aqui conduzido busca comentar inicialmente alguns aspectos pontuais da referida instituição, procurando enfatizar em seguida o enorme entusiasmo que ali gravitava em torno das lides literárias. Para finalizar, são então examinados os traços maiores do inusitado sistema de representações em que tal entusiasmo se apoiava, tentando integrar seus elementos num sentido um pouco mais amplo. Em linhas gerais, o objetivo do artigo é delinear e compreender algumas das possíveis relações que, na metade do século passado, ainda se estabeleceriam entre cultura, livro e intelectualidade.

Palavras-chave: História cultural; História da palavra impressa; Intelectuais brasileiros.

Abstract: This article is a brief attempt to think about the many ideas and representations built in the past about the book universe. The research which originated it was exclusively done by examining the mail received and kept by the former Centro Cultural Euclides da Cunha, in Ponta Grossa, Paraná, Brazil. In structural terms, this study seeks to comment, initially, some punctual aspects of the referred institution, emphasizing, in sequence, the enormous enthusiasm which gravitated around the literary battle. To conclude, the larger traces of the unusual representation system on which such enthusiasm was based are, then, examined, trying to integrate the elements in a little broader sense. In general terms, the aim of the article is to outline and understand some of the possible relations which, in the middle of the last century, would be still established between culture, books and intelligentsia.

Keywords: Cultural History; History of the pressed word; Intellectual Brazilians.

\section{Introdução}

Tudo isto vai longe e pretérito, mas a vida se renóva no vigor da geração presente, como as rosas-detodo-ano, para ornamentá-la indefinidamente pelo tempo e pelo espaço afóra. Augusto Faria Rocha ${ }^{2}$

\footnotetext{
- Mestrando em História - Programa de Pós-Graduação em História - UNESP - Univ. Estadual Paulista, Campus de Assis - Av. Dom Antonio, 2100, CEP: 19806-900, Assis, São Paulo, Brasil. Bolsista do CNPq. Professor Colaborador do Departamento de História da UEPG. E-mail: itamarlopes@,rocketmail.com

- Professor Doutor - Departamento de História - UEPG - Universidade Estadual de Ponta Grossa - Av. General Carlos Cavalcanti, 4748, CEP: 84030-900. E-mail: denipoti@ig.com.br
} 
Este texto encerra uma breve tentativa de se pensar algumas das muitas ideias e representações construídas no passado sobre o universo do livro. Em termos mais precisos, ele procura iniciar uma reflexão mais atenta sobre os pressupostos, implícitos ou não, que na metade do século passado ainda pautavam o desempenho e a atuação de muitos grupos de intelectuais no Brasil.

Partindo assim destes apontamentos, o presente artigo buscará delinear e compreender algumas das possíveis relações que então se estabeleceriam entre cultura, livro e intelectualidade. A formulação destas questões, bem como a maneira encontrada de adentrá-las, se deu por meio do exame de um corpus documental particularmente interessante: as correspondências recebidas pelo extinto Centro Cultural Euclides da Cunha (CCEC), uma agremiação de intelectuais que funcionou de 1948 a 1985 na cidade de Ponta Grossa, no Paraná. Essas correspondências, produzidas e acumuladas pela instituição ao longo do exercício de suas atividades, foram trabalhadas dentro de um recorte temporal que se iniciou em 1948 e se estendeu até 1959, quando se observa uma drástica diminuição no número de cartas recebidas (ver Tabela 01$)^{3}$

Tabela 01 - Correspondências recebidas pelo Centro Cultural Euclides da Cunha de Ponta Grossa. Série: Correspondência Recebida; Sub-série: Correspondências - Centro Cultural Euclides da Cunha.

\begin{tabular}{|c|c|}
\hline Ano & Quantidade \\
\hline 1948 & 18 \\
\hline 1949 & 101 \\
\hline 1950 & 60 \\
\hline 1951 & 60 \\
\hline 1952 & 81 \\
\hline 1953 & 78 \\
\hline 1954 & 46 \\
\hline 1955 & 31 \\
\hline 1956 & 20 \\
\hline 1957 & 34 \\
\hline 1958 & 27 \\
\hline 1959 & 16 \\
\hline
\end{tabular}

Fonte: (GOMES, 1997, p. 87).

Estruturalmente, os resultados desta pesquisa são aqui apresentados em quatro itens, que procuram respectivamente: a) levantar algumas informações gerais sobre o CCEC; b) enfatizar o 
entusiasmo singular que ali gravitava em torno das lides literárias; c) investigar mais detidamente o conjunto das representações em que tal entusiasmo se apoiava; d) tentar compreender e apontar possíveis relações que estes elementos mantinham entre si, dentro de um quadro mais amplo.

Antes de seguir em frente, porém, gostaríamos de incluir mais duas palavras de justificativa, que servirão tanto para o nosso intento no presente artigo, quanto para reafirmar a legitimidade da pesquisa sobre o que se convencionou chamar de "universo da palavra impressa" (ROSE, 2003). Devemos nos lembrar, afinal, que no momento vivemos o acesso a todo o patrimônio escrito da humanidade, ainda que de modo virtual, e isso parece finalmente possível através das possibilidades abertas pelas novas tecnologias digitais. Neste caso, uma reflexão sobre o mundo dos livros e dos intelectuais é sem dúvida bastante oportuna, principalmente se considerarmos o fato de que essa reflexão se assenta no uso de cartas escritas, cujos gestos específicos não constituem mais os nossos. A troca e a circulação de informações através de dispositivos eletrônicos pessoais como microcomputadores e aparelhos de telefone celular, que caracterizam e marcam profundamente nossa sociedade contemporânea, constituem uma nova economia e exigem igualmente uma outra gestão da informação. Em longo prazo, as rupturas decorrentes deste mesmo processo poderão acarretar sérios problemas ao trabalho dos historiadores.

Diante disso, qual seria, afinal, a pequena contribuição desta pesquisa? Em que medida nossa limitada reflexão poderia ajudar na abordagem das questões suscitadas por essas novas tecnologias? Para responder a tais perguntas poderíamos fazer nossas as palavras de Roger Chartier (1999, p.10): "Reintroduzindo a variedade e a diferença, lá onde surge espontaneamente a ilusão do universal, ela nos ajuda a nos desprendermos de nossos limites muito seguros e de nossas evidências por demais familiares".

\section{O Selecionado Sodalício}

O estudo do material acumulado pelo CCEC não constitui um feito inédito. Há pouco mais de dez anos, a historiadora Carmencita de Holleben Mello Ditzel (1998) procurou elucidar algumas questões referentes à criação, ação e significação educacional da instituição junto à cidade de Ponta Grossa, e mais recentemente o rico acervo documental ${ }^{4}$ deixado pelo órgão se tornou alvo de um projeto que reúne vários estudantes e pesquisadores. ${ }^{5}$

Segundo Ditzel (2001, p.211-212), as raízes do CCEC remontam ao século XIX. Mais especificamente, é ao processo de "nacionalização cultural”, encetado pelo Romantismo, que ela atribui as condições da sua criação. Sentido com um vigor desigual na literatura, o impacto deste processo não é menos pujante no campo da história: em 21 de outubro de 1838 funda-se, no Rio de Janeiro, o Instituto Historico e Geographico Brasileiro, incumbido a partir de então de forjar uma 
história e um passado para a nação recém-emancipada (SCHWARCZ, 1995, p.101). "Essa tradição originária do século XIX permanece na contemporaneidade e chega a cidades afastadas dos grandes centros culturais, como Ponta Grossa. Herdeiro desta tradição surge o CCEC” (DITZEL, 2001, p.212).

Fundado então em 1948 e presidido por Faris Antônio Salomão Michaele ${ }^{6}$ até 1977, o CCEC manteve-se funcionando até meados de 1985. Em linhas gerais, ele se estabeleceu como uma agremiação intelectual formalmente instituída, que procurou patrocinar e estimular as discussões em torno do que se entendia por cultura naquele momento. Assim, e sob a égide do autor de Os sertões, o grupo buscou congregar forças no sentido de se fomentar o desenvolvimento da literatura, das ciências e das artes, estimulando o intercâmbio de ideias entre as demais regiões do país e das Américas. No quadro de seus associados estiveram presentes eminentes personalidades da cidade de Ponta Grossa: militares, professores, advogados, comerciantes, artistas e escritores, médicos e políticos locais partilharam e participaram das atividades que cercavam os ideais da instituição.

A presença e a atuação do CCEC, no entanto, não ficaram restritas apenas à esfera local ou ao território paranaense. Os euclidianos de Ponta Grossa mantinham-se em contato frequente com diversas instituições espalhadas pelo Brasil, e seus laços chegavam mesmo a ultrapassar os limites do país. $\mathrm{Na}$ documentação gerada pelas atividades do órgão em questão encontram-se várias evidências que comprovam tal afirmação. As cartas, os livros e outros papéis chegavam enfim de todos os lugares: Chile, Argentina, Uruguai, Peru, Equador, Estados Unidos, Portugal, Itália, etc.

Quanto ao funcionamento propriamente dito, a instituição ponta-grossense não fugia à regra de suas congêneres nacionais:

Para a consecução de suas finalidades, o Centro explicita[va] em seu estatuto as suas atividades primordiais: realização de cursos, conferências, palestras e reuniões culturais; divulgação de obras científicas, literárias e artísticas nacionais e dos demais países americanos; publicação de um jornal trimestral; organização de uma biblioteca e sala de leitura; realização de maratonas intelectuais periódicas para estimular na juventude o gosto pelas ciências, letras e artes (DITZEL, 2001, p.213).

Há, certamente, uma profunda ligação entre o papel ou função da palavra impressa na sociedade de um modo geral e essa é a razão de ser de uma instituição como o CCEC. Estimular na juventude o gosto pelas ciências, letras e artes, afinal, é preciso também incitar nela o hábito da leitura e o apego aos livros. Não podemos nos esquecer, além do mais, que naquele momento a palavra impressa desfrutava ainda de um enorme prestígio enquanto forma tradicional de transmissão de conhecimento. Deste modo, a lógica de atuação e a própria existência da instituição preconizavam uma proximidade - largamente difundida - entre noções precisas de cultura, livro e de intelectualidade. 
Diante disso, o nosso objetivo é procurar aprofundar algumas destas questões, relacionando-as com os apontamentos e conclusões parciais de alguns historiadores dentro da temática do livro e da leitura. Mas como poderemos penetrá-las, dadas as décadas que nos separam deste universo do passado? Uma das maneiras que encontramos passa pelo exame minucioso de um corpus documental particularmente interessante: as correspondências recebidas pelo extinto CCEC, de Ponta Grossa.

Ao longo do exercício de suas atividades, o CCEC acumulou um rico acervo de cartas que hoje constitui matéria-prima para inúmeros trabalhos acadêmicos. Como aponta Josélia Gomes (1997, p.86-87), existem dois fundos diferentes nos quais se distribuem estas correspondências: o acervo do CCEC, e o acervo particular do professor Faris Michaele. Neste último caso, as correspondências recebidas somam um total de 780, compreendendo o período que vai de 1922 a 1989. Existem também alguns rascunhos de cartas enviadas por Faris, tanto manuscritas quanto datilografadas, mas que foram preservadas apenas eventualmente, já que o mesmo não tinha o hábito de manter cópias.

No que toca à série de cartas do CCEC, organizada em ordem cronológica e dividida em duas outras sub-séries, encontramos os seguintes números: 728 correspondências endereçadas ao Centro para o período de 1948 a 1981, e 1456 cartas remetidas ao professor Faris Michaele, abrangendo os anos de 1934 a 1976. O presente trabalho se construiu a partir do exame de cerca de 400 dos 728 documentos endereçados ao CCEC, selecionados e distribuídos entre 1948 e 1959. Para além das formalidades encerradas na confluência institucional, a análise desta documentação nos permite observar uma dimensão mais subjetiva das relações estabelecidas não só entre os membros da agremiação de um modo geral, mas também com o mundo dos livros em particular. Nas cartas, os correspondentes os mencionam e fazem glosas, os enviam e os solicitam, citam os seus próprios livros ou ainda pedem ajuda para publicá-los. Assim, as questões que são aqui investigadas tratam especificamente deste universo, de suas implicações junto a um determinado grupo e, por conseguinte, junto à sociedade em que este grupo se insere e/ou se relaciona. Essas indagações giram em torno de perguntas como: o que exatamente essas práticas significavam para o grupo de pessoas ligado ao CCEC? O que elas representavam no curso comum de suas vidas e como isso transparecia nas correspondências? Ou ainda, de modo mais incisivo: haveria algum tipo de relação particular entre as práticas ligadas ao mundo dos livros e o papel social a ser desempenhado junto à instituição? Enfim, procura-se compreender, através das correspondências, como essas pessoas pensavam o universo do livro na esfera social de suas vidas.

Contudo, antes de nos debruçarmos sobre as representações da palavra impressa tentaremos encontrar uma maneira que nos possibilite adentrar o universo dos intelectuais euclidianos. Em outras palavras, é preciso tentar reconstruir e recuperar a coerência própria dos seus elementos, 
frequentemente ofuscados pelo passar dos anos, para que se possa, então, compreender o papel e a inserção social do livro nesse momento. A maneira pela qual isso se torna possível ao historiador de hoje é, na opinião de Paul Veyne (1987, p.198), convenientemente a mesma que viabilizou aos indivíduos a inteligibilidade e normalidade características de um determinado período da história. A seriação ${ }^{7}$, portanto, passa a ser a grande ferramenta do historiador por muitas razões. Mas entre essas há uma que se mostra fundamental:

Essa razão é que, segundo as ocorrências recolhidas são mais ou menos numerosas, conclui-se que, para o período escolhido o facto, o costume, a palavra cujas ocorrências recolhemos se recortam ou não sobre a norma da época. Ora, na visão que as pessoas têm da sua própria época, esta idéia de norma tem uma grande importância: ela dá ao seu mundo ambiente o ar de familiaridade, de quotidianeidade; e esta consciência de quotidianeidade vem-lhes do mesmo método de seriação que praticará face a ele o futuro historiador: a indução ensinou-lhe a distinguir, no que as envolve, os fenômenos banais das singularidades que recortam (VEYNE, 1987, p.198).

É justamente esse coeficiente de cotidianidade que é corrompido pelo passar do tempo. A banalidade que estruturava a vida no passado, dessa forma, transforma-se em algo totalmente distinto no presente. Ela se transfigura no que hoje foge à norma vigente, ou seja, naquilo que escapa às séries contemporâneas recorrentes; torna-se com frequência o surpreendente, o exótico, a piada. A tarefa do historiador, diante disso, é a de tentar reconstruir essa cotidianidade. Dito de outra forma, trata-se de contextualizar: devolver as práticas, os costumes, os comportamentos, à série mesma de que faziam parte anteriormente. Como asseverou corretamente Alain Corbin (1989, p.7), "não há outro meio de conhecer os homens do passado a não ser tomando emprestado seus olhares, vivendo suas emoções”.

Nesse sentido, os resquícios de sociabilidade preservados na documentação que nos propusemos trabalhar oferecem ao leitor a oportunidade única de compartilhar parte das emoções que animaram um determinado grupo de pessoas, num determinado momento da sua história. Assim, quando elas transgridem nas cartas o campo das formalidades e passam a confidenciar os aspectos e dramas da vida pessoal, abrem hoje uma janela para que o historiador possa perscrutá-la. Melhor dizendo, talvez abram apenas uma pequena fenda no tecido espesso que a cobre de seu olhar sempre curioso. Seja como for, tratemos de aproveitar a oportunidade que se nos apresenta neste momento; tentemos explorar as informações disponíveis nos documentos e contemplá-las despojados da ideia ingênua de passado que estamos por vezes habituados a reproduzir. 


\section{Os que se dedicam às Lides do Espírito}

Em algum momento do dia 27 de outubro de 1948, em Curitiba, um certo Durval Borges registrava à máquina seus agradecimentos e em tom de gratidão enviava "à biblioteca [...] alguns livros e revistas". ${ }^{8}$ Pouco mais de três meses depois, em fevereiro do ano seguinte, alguém, cuja grafia escondeu-nos o nome, também remetia do Rio de Janeiro alguns trabalhos seus, bem como um drama de autoria de seu pai. ${ }^{9}$ Em março, nesta mesma cidade, era a vez de Alcântara Nogueira, que em breve prometia enviar dois livros seus, um dos quais - o principal, diz ele - na eminência de ser entregue ao editor. ${ }^{10}$

Independentemente da autoria ou do título, do tema ou da proveniência, os livros e trabalhos literários são figuras constantes nos textos dessas correspondências. Na mais remota das hipóteses, e sem a menor dúvida, tais motivos certamente devem ter ocupado tempo e espaço consideráveis nas vidas dessas pessoas; devem ter mobilizado suas existências, e forjado, em parte, suas identidades. Em última análise, estas questões devem ter tido um significado que agora irremediavelmente nos escapa.

De fato, os sessenta anos que nos separam desse momento preciso parecem iludir-nos quanto à sua pertinência histórica. Comparados, por exemplo, com o enorme intervalo que nos separa dos homens do século XVI, esse curto espaço de tempo aparenta certa insignificância em termos de mudanças de pensamento e de comportamento. Somos, assim, tentados a estabelecer que os autores das cartas que hoje temos em mãos eram exatamente os mesmos que transitam hoje nas calçadas de nossas cidades. Assim, procurar reencontrar a coerência, captar os acidentes, declives e curvas próprias de um determinado período exige antes de tudo uma postura de estranhamento diante deste. Como observa Robert Darnton (1986, p. XV), é preciso que abandonemos de vez nossa "falsa impressão de familiaridade com o passado", começando pela ideia de se "captar a diferença". Dito ainda de outra forma, o historiador - ou o pesquisador - deve portar-se frente a esse passado tal o antropólogo diante de uma cultura estrangeira. A sugestão de Darnton, nos termos acima referidos, vale como um novo alerta ao "velho" problema do anacronismo, pois embora pareça tratar-se de uma questão há muito superada, é preciso admitir que não estamos livres de cair em armadilhas e incorrer em equívocos interpretativos.

No que diz respeito a este estudo, o estranhamento a que se refere Darnton nos foi provocado, em parte, pelo grande entusiasmo que mobilizava as atividades do grupo humano ligado ao CCEC. Ao se entrar contato com as cartas e com outros documentos deixados pelas pessoas que o constituíam, é realmente difícil não se surpreender com o fervor singular que alimentava a busca por seus ideais. Se é para nós difícil compreender ou captar no presente esse acendimento característico, isso se deve tanto ao fato de que não somos contemporâneos desses indivíduos, 
quanto ao de não pertencermos ao grupo específico que integravam. A despeito de sua aparente simplicidade, esta ideia aponta em direção a uma questão fundamental: surpreendemo-nos com as atitudes destas pessoas - apreendidas através dos documentos que deixaram e que chegaram até nós - pois não compartilhamos dos códigos comportamentais próprios que orientavam suas condutas naquele momento; ou seja, porque não nos é dado compreender de imediato o feixe de representações em que estavam assentadas suas experiências.

Nesse sentido, o diletantismo característico com que os indivíduos tratam nas cartas os assuntos e os temas relacionados ao mundo dos livros, pode nos dar uma vaga ideia da importância por eles atribuída a tais atividades. Ser indicado a compor o quadro euclidiano ponta-grossense, nas palavras de J. de Souza Ferreira, era ter "a sensibilidade [...] tangida por honraria de tão alto quilate", que ofuscaria indelevelmente qualquer esboço ou expressão de gratidão. ${ }^{11}$ Para S. A. Sanders, tal admissão parecia envolta num sentido muito mais prático, na medida em que fortalecia nele

o propósito de que de então pra cá me sinto animado, qual o de, em me estando nas posses, oferecer àqueles que me deram de sua magnífica e inequívoca hospitalidade provas irrecusáveis, um pouco - se não resvalo em veleidade em lhes dando testemunho - das forças que me formigam no braço e do entendimento que me bruxoleia no encéfalo. ${ }^{12}$

Essa empolgação, repetimos, caracteriza boa parte das correspondências aqui trabalhadas. A carta de João Pereira a Faris Michaele parece ser igualmente exemplar nesse sentido, e pode nos ajudar a explorar um pouco mais os sentimentos que animavam não apenas ele, mas também muitos outros de seus confrades. Assim, quando renovava seus agradecimentos à recente nomeação como sócio-correspondente do CCEC, Pereira escrevia em 1949 as seguintes palavras:

Desde o momento em que recebi a comunicação de haver ingressado nêsse sodalício, até agora, tem-me sempre dominado o ânimo, [...] o temor de não estar à altura de tamanha honra. [...] porém, [...] se, para tê-la, me escassearem a inteligência e, do mesmo passo, o saber que se não podem escusar nas agremiações da natureza dessa [...] o que, positivamente, me não minguará há-de ser entusiasmo no desempenho dos encargos que me forem dados. ${ }^{13}$

Este é também outro dos temas recorrentes na documentação analisada. Um detalhe importante que não deve ser ignorado é que a evocação desse "entusiasmo" é frequentemente contraposta a uma "bagagem intelectual nem sempre condizente". Funcionaria o entusiasmo como uma espécie de contrapeso no processo de admissão? Ou seria apenas uma fórmula vazia travestida de falsa modéstia? No trecho seguinte da correspondência, João Pereira parece sugerir a existência de outras razões. Dizia ele: 
Triste do homem que se não constrange de receber um pôsto de eleição, ou de nomeação, com a mira feita em lhe não dar o melhor de sua inteligência e de seus esforços. Os que ocupam lugares, pouco fazem êstes, movidos únicamente do desejo estulto de brilhar, de mostrar-se, de aparecer, ou, então, levados da ânsia de alcançar haveres e comodidades, êsses são daqueles que jamais hão-de concorrer para tornar a Pátria venturosa e grande. A esta, só a farão feliz e considerada, os que vão para os postos, que os fados lhe designaram, sem a néscia preocupação de se fazerem vistos, e, ainda, sem ambições de enrequecimento [sic], pois tudo isto é próprio, apenas, das almas órfãs de idealismo. ${ }^{14}$

Ora, segundo o que o próprio João Pereira dá a entender, o entusiasmo seria justamente o elemento de distinção entre os que concorreriam para o bem e a felicidade da pátria e aqueles que, por sua vez, não o fariam. Todavia, estar entre os primeiros implicava também a renúncia aos desejos de projeção individual, bem como às ambições vãs e de enriquecimento. Era necessário, com efeito, anular-se frente ao coletivo, agregar-se a ele "sem a néscia preocupação de se fazer visto", e isso em função de um "idealismo" ausente nos espíritos cúpidos. "Acolhestes o mais frágil e o mais desvalioso Amigo à sombra confortadora de seu Idealismo”, observava, em 1951, o "diletante" Adar de Oliveira e Silva sobre o "gesto de deferência" que o integrava ao grupo. ${ }^{15}$

Um outro corolário desse tipo de argumento é a insistente recorrência ao adjetivo "obscuro", que se faz notar em um grande número de situações nas correspondências. Augusto Faria Rocha é exemplo de uma delas. No entanto, ao escrever de Antonina, no Paraná, em reconhecimento à eleição unânime de seu "obscuro nome" para sócio-correspondente do CCEC, ele acaba nos ajudando a pensar também a questão inicial da importância da prática intelectual naquele contexto. Assim, a certa altura, comentando seu ingresso na instituição diz não enxergar

no fato senão o traço marcante do tradicional cavalheirismo de que é apanágio a galharda mocidade intelectual da linda metrópole campesina, cuja atividade, trepidante e multifária, ainda póde possibilitar, aos cultores das belas letras, o mél do espírito, à maneira das abelhas encantadas de Pindaro. ${ }^{16}$

Ao final de seu texto, Faria Rocha reforça a reincidente associação dos intelectuais da cidade a uma "juventude ilustrada", e acrescenta ainda acerca do diploma recebido: "uma dádiva demasiada alta, mas, afinal, tentadora". ${ }^{17}$ Consoante a essa mesma ideia, Raimundo Maranhão Ayres, presidente da Associação de Intercâmbio Cultural de Guiratinga, no Mato Grosso, nos informa em carta de 22 de junho de 1949 que o "ilustrado confrade e companheiro Dr. João Brito Jorge, escritor e jornalista de abastado prestígio em nosso país [...] muito honrado ficaria se lhe fosse possível ingressar no quadro de sócios dessa egrégia instituição de cultura" ${ }^{18}$ Como reitera adiante seu proponente,

a aquisição de Brito Jorge [seria] de grande expressão para essa brilhante entidade, podendo o mesmo prestar com larga eficiência e inteligência largos serviços, 
tornando-a mais divulgada, através especialmente dos jornais cariocas, onde exerce as funções de redator, mormente de A NOITE no Rio. ${ }^{19}$

Contudo, o que realmente nos parece sintomático neste pequeno episódio é que a sugestão de Ayres vem acompanhada e devidamente reforçada de uma ficha bio-bibliográfica do referido jornalista. A constatação de que não se trata de um caso isolado nos leva tanto a verificar a importância atribuída à produção bibliográfica nesse meio em particular, quanto a questionar até que ponto tal documento poderia de fato facilitar o ingresso numa instituição como o CCEC. Não obstante, a situação que envolve essas duas personagens também nos deixa entrever algo da projeção nacional e do capital representativo que gravitavam em torno do estabelecimento pontagrossense.

O que deve ser destacado, com efeito, é que todos os aspectos que foram até aqui comentados estavam estreitamente ligados ao viver diário dos integrantes do grupo euclidiano. Afinal de contas, é forçoso reconhecer que o entusiasmo pela causa deveria mesmo ter um papel de destaque para indivíduos que precisavam conciliá-lo não só com o cotidiano do trabalho, mas também com os compromissos familiares da vida privada e com outras diversas atividades simultâneas. Era justamente esta a queixa do mesmo Raimundo Maranhão Ayres a Faris Michaele nos idos de 1954. Nesta ocasião, escrevia ele:

As ocupações e os encargos que se acumulam cada dia, neste movimento intenso de intercâmbio consomem o nosso tempo de forma tal que não nos possibilita trazer em dia a nossa correspondência. Vivemos sempre em atrazo com os amigos, por mais que trabalhemos, por mais que nos dediquemos com carinho [...] ao ideal e a causa que constitue o nosso maior enlevo, a nossa maior preocupação espiritual. $\mathrm{O}$ que consigo acontece é o mesmo que se verifica comigo. Tenho casa comercial, Escritório de cobrança, Representações, Jornal, Associações, enfim esta série imensa de encargos e cuja correspondência sou eu exclusivamente que a redijo. Mesmo em nossa A. I. C. [Associação de Intercâmbio Cultural] apezar dos vários secretários que possue, nenhum deles se incumbe de qualquer ou encargo semelhante. Diante disto o peso sobre meus ombros é grande demais e o tempo exíguo para tudo atender prontamente. ${ }^{20}$

Antecipando-o em alguns anos, em 12 de abril de 1950, Nilo Brandão também legava à posteridade sua reclamação: "A minha vida complexa, sempre inferior em tempo e forças aos deveres que a sobrecarregam", dizia ele, "não raro me faz retardar gratas obrigações, que eu desejara cumprir imediatamente". ${ }^{21}$ A maior delas, segundo o que o próprio Brandão nos diz adiante, era agradecer àqueles que indicaram seu nome a desempenhar as funções de sóciocorrespondente do CCEC em Curitiba.

Algo semelhante parece ter acontecido com Alcyone Moraes Vellozo, médico em Curitiba, quando, no início de outubro de 1951, também escrevia ao secretário do CCEC escusando seu involuntário "deslize”. Como na carta vista logo acima, o atraso na resposta era atribuído por ele a 
"demasiado trabalho e imprevistas dificuldades", e não devia ser tomado como indiferença. Tentando deixar isso às claras ele registrava as seguintes palavras:

Espéro do alto espírito de comprehensão de todos os caros confreires deste renomado Centro o perdão por essa minha falta que muito me angustia ao pensar que possa parecer uma falta de atenção ou de acatamento ao gésto que muito desvaneceu e muito me honra de ter sido proposto, aceito por unanimidade e conferido o Diploma de Sócio Correspondente, deste brilhante Cenáculo, que através de um trabalho constructivo vem engrandecendo as letras de nossa Terra. ${ }^{22}$

Contudo, nem o tempo atulhado e nem mesmo os afazeres corriqueiros da vida diária impediam alguma dedicação aos labores intelectuais. À sua maneira, o testemunho de Heloísa Alberto Tôrres demonstra essa situação. Aos 23 dias de janeiro de 1952, ela declarava:

[...] que esse meu sentimento de admiração acompanhado da maior simpatia vem, de há muito, seguindo o "Centro" e que, no atropêlo da vida por demais sobrecarregada que levo, sempre encontro uns momentos de folga para ler o seu jornal tão cheio de inquietação e atividade intelectual. ${ }^{23}$

Poderíamos continuar a estender indefinidamente a lista de exemplos, mas não parece ser necessário. Os indícios verificados na documentação e aqui apresentados são unânimes em apontar a seriedade e o comprometimento envolvidos na prática desses intelectuais. Muitos deles dedicaram anos de suas vidas aos ideais que animavam o grupo, e o fizeram com um fervor apaixonado cujas cores se desbotaram à medida que os anos se precipitavam. Quando nos deparamos hoje com testemunhos semelhantes ao de S. A. Sanders, por exemplo, ou ainda com a riqueza dos termos e adjetivos dirigidos à instituição presentes em certas cartas, temos a certeza disso; temos a certeza de que há um abismo entre presente e passado, e que considerar a dimensão simbólica deste último é um elemento indispensável à sua compreensão. Embora seja preciso relativizar e prestar certa atenção às funções e formalidades específicas do documento em questão, não podemos ignorar por completo seu caráter pessoal. $\mathrm{O}$ aspecto subjetivo a que esta modalidade de fonte permite ter acesso direto é de um valor singular ao historiador, seja qual for sua tendência teórico-metodológica. Tratase, não obstante, de uma outra dimensão da história que é às vezes posta de lado quando procedemos à sua reconstrução: a dimensão humana. Pois é necessário sempre ter em mente que por detrás do processo criminal, do inventário, dos arquivos paroquiais ou do relato do jornal, existiram pessoas. É frequentemente delas que falamos: dos seus sofrimentos, dos seus anseios e de tudo o que lhes diz respeito; em uma palavra, das suas vidas. Enxergar a história levando em conta essas duas dimensões acaba por aproximar presente e passado, o que, em termos metodológicos, talvez signifique menores dificuldades no trabalho de delimitação e diferenciação de ambos. 
Assim, foi dentro desse quadro que procuramos estabelecer um primeiro diálogo com as correspondências, demonstrando ligeiramente alguns traços específicos de seu contexto. O que se pôde perceber, nesse sentido, foi que aí se atribuía uma grande importância às atividades ligadas ao meio intelectual. De certo modo, esse apego aos livros e aos labores intelectuais parece configurarse como característico deste período, pois estamos certos que o perfil da maioria dos indivíduos envolvidos com o grupo euclidiano ponta-grossense poderia ainda ser descrito em termos semelhantes ao de Dario Vellozo, homem que viveu em Curitiba até 1937.

Dario vellozo estava envolvido no mundo do livro, não somente pela leitura, mas em todo o processo de produção, criação e divulgação da palavra impressa. A forma intensa como ele leu os simbolistas, os "pitagóricos" e os autores locais demonstram uma profunda dedicação a este universo. Como personagem exemplar do apego que seu tempo atribuía ao livro, Vellozo penetrou mais do que a maioria de seus contemporâneos nesse universo, carregando no processo algumas dezenas de seguidores mais empenhados. Seu envolvimento com a leitura e o mundo do livro foi a chave para seu reconhecimento naquela sociedade, que inicialmente fechou-se provincianamente a ele, mas que elevou-o ao patamar de um de seus maiores expoentes intelectuais.

Vellozo foi um exemplo extremo desse envolvimento com o mundo da leitura, mas de forma alguma esteve sozinho. Sua dedicação aos livros encontrou eco em um meio bastante fecundo, onde a palavra impressa marcava o comprometimento com idéias de nação, pátria, civilização, arte, ciência, etc. (DENIPOTI, 2001, p.86).

Como foi possível observar, divulgação de obras escritas e constituição de biblioteca estavam também entre as atividades primordiais do CCEC. Da mesma forma, os leitores/escritores que o integravam demonstraram talvez o mesmo empenho e dedicação que caracterizou o perfil de Dario Vellozo. Esse tipo de comportamento inscrevia-se, portanto, em meios ainda bastante semelhantes.

Essas constatações, no entanto, levam-nos a uma outra ordem de problemas. Se as ideias e as bandeiras do CCEC não passavam na verdade das ideias daqueles que o constituíam, elas podem ser tomadas como algo muito mais profundo. Numa certa medida, elas seriam anteriores à fundação da instituição e estariam ligadas ao próprio processo de formação idiossincrática de seus membros. De acordo com esse raciocínio, as concepções partilhadas por um determinado estrato da sociedade seriam geradoras de comportamentos que, por sua vez, exprimiriam um modo característico de ser, estar e pensar o mundo à sua volta. A distribuição dos papéis, a ordenação, a atribuição de sentido e a própria intervenção na sociedade seriam em parte decorrentes desse mesmo processo. Deste modo, após um rápido passeio pelo universo particular dos autores e das cartas que deixaram, restanos investigar mais de perto o conjunto das representações que tornaria possível a manutenção de tais condutas. 


\section{Mourejadores, Obreiros e Trabalhadores}

São inúmeros os termos utilizados nas cartas para se referir ao CCEC. De certa forma, eles apontam justamente para nossa incompreensão frente ao que a instituição poderia ter representado no passado. Mas não apenas para isso. Esses mesmos termos ainda parecem ter mais a nos dizer, principalmente no que diz respeito à desarticulação e à descontinuidade que os caracteriza.

Nesse sentido, a ausência de um consenso geral nas qualificações dirigidas ao CCEC parece ser sintomática. Nas diversas ocasiões em que aparecem expressões como "douta instituição literária", "Centro literário e cultural”, "conceituada agremiação literária”, “egrégia instituição de cultura", entre outras - e que, às vezes, coabitam o mesmo texto -, o que se percebe, na verdade, é uma espécie de equivalência lexical entre aquilo que se designa por "cultura", e o trabalho ou o campo de ação do intelectual. Ora, se no modo como as pessoas materializavam as relações entre essas duas noções - na escrita, portanto - ocorriam intersecções ou interpenetrações mútuas, depreende-se que, no seu modo de pensar, ambas estavam de certa forma muito próximas. Indo um pouco mais longe, pode-se afirmar novamente que, no contexto específico deste estudo, conceitos como cultura, intelectualidade e labor literário - bem como o produto deste próprio labor (o livro ou, mais genericamente, a palavra impressa) se confundem num quadro extremamente complexo de interdependências, de maneira que se torna impraticável tomá-los como categorias ou noções isoladas.

Outro elemento que reforça a hipótese acima esboçada é que a equivalência de sentido que demarcava as qualificações dirigidas ao CCEC se estendia também à esfera pessoal e subjetiva dos indivíduos que o integravam. Deste modo, quando esses se referiam às suas capacidades, o faziam por vezes como Agnello Bittencourt em agosto de 1952. Nessa ocasião, ele assegurava sua atenta colaboração à causa da instituição, porém na medida e no alcance do "pequeno cabedal de inteligência e cultura" que era o seu. ${ }^{24}$ Ao aceitar a nomeação para sócio correspondente em Curitiba, Felizardo Gomes da Costa proclamava também “a ausência de bagagem literária ou intelectual que [...] [o] credenciasse merecedor" do referido cargo. ${ }^{25}$ Posteriormente, em setembro de 1951, Paulino Santiago falava em "congraçamento dos trabalhadores intelectuais da [...] Pátria" ${ }^{26}$ Assim, e a exemplo desses, muitos outros também "confundiram" seus méritos "intelectuais" com os méritos "culturais" e/ou "literários", dando a entender que haveria então uma estreita correlação entre estas noções.

Não obstante, junto a esse emaranhado de ideias estavam também - como vimos nos itens anteriores - o fervor e a paixão de uma coletividade que viveu concretamente tudo isso, e o que é mais importante, o fez de uma maneira bastante singular. Precisar o que de fato significou esta experiência está além das possibilidades do historiador. Como disse Carlo Ginzburg (1987, p. 34) a 
respeito do caso-limite de Menocchio, o moleiro friulano queimado pelo Santo Ofício no século XVI, é somente através de um gesto arbitrário que podemos incorporar os fragmentos de uma cultura perdida à nossa própria história. Porém:

Respeitar o resíduo de indecifrabilidade que há nela [na cultura perdida do passado] e que resiste a qualquer análise não significa ceder ao fascínio idiota do exótico e do incompreensível. Significa apenas levar em consideração uma mutilação histórica da qual, em certo sentido, nós mesmos somos vítimas (GINZBURG, 1987, p.34).

Em parte, foi a essa mutilação que conferimos inicialmente alguma atenção. Num primeiro momento, ao nos debruçarmos sobre os fragmentos esparsos de um contexto histórico distinto, o que pretendíamos era, na verdade, afastar toda e qualquer reserva ainda restante para com o passado. A não observância dessas precauções acabaria impedindo-nos de enxergar aspectos importantes à sua compreensão, como, por exemplo, a seriedade e o acendimento característicos que marcavam de modo indelével o desempenho das funções e atividades ligadas ao CCEC. Quando olhada de modo mais atento, tal performance aparece estreitamente vinculada ao complexo de ideias que enredava o grupo. Esses pensamentos, somados a tudo o que vimos anteriormente, poderiam integrar aquilo que chamaríamos a cultura da elite letrada da época. Mas é melhor não alargar demais as fronteiras deste debate. De um modo geral, contudo, pareceu-nos muito claro que o grupo de intelectuais congregados a trabalhar pelo incremento da cultura - tanto local como nacional - partilhava das mesmas concepções quanto ao que constituiria ou envolveria este trabalho. Por mais confusas ou ambíguas que fossem as tentativas de defini-lo, elas apontam claramente em direção a algumas noções específicas: o campo de ação do intelectual situava-se no encontro de ideias de arte, literatura, ciência, nação, civilização, etc. Por sua vez, a palavra impressa (livros, jornais, etc.) desempenhava um papel fundamental junto a essas relações.

Na verdade, a concepção de cultura compartilhada pelos autores das cartas apresentadas - que encerrava talvez a mesma imprecisão que o designativo "intelectual”, já que estavam estreitamente vinculados - era parte integrante de um sistema de apreciação bastante característico. Ele fornecia, por sua vez, os elementos subsidiários necessários à alocação e organização social do grupo de um modo geral. Em outras palavras, engendrava uma maneira determinada de se situar, ver e pensar o mundo à sua volta. $\mathrm{O}$ processo de elaboração dessas representações, portanto, aparece profundamente atrelado à questão da atuação prática no meio social. Ora, de acordo com Roger Chartier (2002, p.61-79), é sobretudo na confrontação destas práticas e representações que se torna possível a compreensão/construção das identidades sociais. Entendendo-as, assim, como frutos de processos dinâmicos de luta e de embates entre representações, ele acredita ser possível superar uma visão empobrecida da história que via as divisões culturais e as identidades sociais como 
reflexos diretos de recortes previamente estabelecidos. Trata-se, em suas próprias palavras, de um "retorno [...] sobre o social [...] que dedica atenção às estratégias simbólicas que determinam posições e relações e que constroem, para cada classe, grupo ou meio, um 'ser percebido' constitutivo de sua identidade" (CHARTIER, 2002, p.73).

Ao longo do trabalho com as cartas foi possível perceber e explorar situações que se repetiam com certa frequência. Durante os dois primeiros itens do texto, ao explorar e apontar algumas dessas situações, identificamos, por exemplo, a existência de um entusiasmo muito grande em torno das atividades culturais e/ou intelectuais. Este entusiasmo, envolto numa rede bastante intrincada de ideias, funcionaria como um elemento de distinção entre aqueles que fomentariam o "bem e a felicidade da Pátria", e aqueles que se apossariam dos postos de nomeação com intenções de “exibição individual e enriquecimento". Como vimos, era necessário anular-se frente ao coletivo em nome de um idealismo bastante evocado. A confirmação disso se dava por meio do emprego de vários adjetivos que, de certo modo, tentavam acentuar o caráter despretensioso da adesão à causa.

Esses elementos certamente estariam presentes no que constituiria a identidade social desse grupo de pessoas. Entretanto, não podemos nos esquecer que o processo de construção de representações envolve também outros aspectos da vida em sociedade. Entre estes, o ser percebido desempenha uma função de grande importância, na medida em que é produzido na confrontação direta com o outro. O estabelecimento de uma maneira própria de figurar no mundo, portanto, passa pela elaboração de uma auto-representação que necessita de credibilidade exterior. Embora nossa análise não seja ampla o bastante para realizar esta confrontação, tentaremos fazer um esforço para perceber como o grupo se representava enquanto coletividade. Uma primeira pista nesse sentido nos é fornecida por um advogado de Curitiba. Em outubro de 1949, a respeito da indicação de seu nome para sócio-correspondente, Manoel de Oliveira Franco Sobrinho dizia o seguinte: “Aceito a escolha como mais um galardão em minha vida de proletário intelectual". ${ }^{27}$ Em circunstância semelhante, Durval Borges assegurava, no mesmo ano: "no mundo das letras, tenho tanto de trabalhador quanto de obscuro". ${ }^{28}$ Newton Souza e Silva, também advogado, escrevia de Ponta Grossa no ano seguinte: "recebo com a maior satisfação a minha entrada nessa Casa, onde se trabalha com altruísmo e sinceridade, pelo engrandecimento espiritual de Ponta Grossa". ${ }^{29}$ O mesmo Felizardo Gomes da Costa, em carta já citada acima, reforçava ainda mais essa imagem ao falar dos "homens bem intencionados, que mourejam por êsse nosso querido e explendoroso Paraná" ${ }^{30}$ Em janeiro de 1954, Gabriel Pinto Assunção também informava: “Tenho, realmente me esforçado grandemente para colaborar com aqueles que trabalham pela felicidade, pela grandeza e pela prosperidade deste nosso portentoso Brasil". 31

Em todos esses casos temos presente a temática do trabalho. O endosso da imagem do trabalhador, entretanto, vem por vezes acompanhado dos adjetivos ou qualificativos legitimadores. 
Como dissemos, era para eles necessário deixar às claras que a adesão ao grupo se inspirava em virtudes e intentos específicos. Dessa forma, os referidos trabalhadores deveriam estar imbuídos de valores como o altruísmo e a sinceridade, que funcionariam como selos de autenticidade na incorporação dos desígnios coletivos. Esse tipo de postura ecoava em declarações como a de Plínio Ayrosa, em março de 1949, dirigida ao corpo da instituição: "Que jamais as preocupações egoísticas, as insídias políticas e as más doutrinas ou filosofias ambíguas empanem, obstem, ou deturpem a firmeza de seus intuitos". ${ }^{32}$ Não obstante, os "homens bem intencionados" precisavam apresentar também a decantada modéstia, pois que seria garantidora das nobres intenções na adesão ao projeto do grupo. Consequentemente, é bastante significativa a insistência no emprego de epítetos como "modesto obreiro", "obscuro sócio", entre outros.

Veremos adiante que esta associação ao trabalho, longe de ser fortuita, estava ligada a uma ideia de cultura bastante original. O intelectual, por sua vez, desempenhava aí um papel fundamental. E se sua atuação, intervenção e participação na esfera cultural se dava, sobretudo, através do intercâmbio de ideias, esse intercâmbio se processava em grande parte por meio da palavra impressa. Desse modo, na confluência desses elementos e dentro da lógica de suas relações, é sem dúvida indispensável que se considere o papel do impresso em qualquer tentativa de se compreender os caminhos, as razões, a ordem e o funcionamento da sociedade na metade do século passado. De maneira semelhante, é preciso que se preste também muita atenção às palavras, às ideias e às atitudes de todos aqueles que devotaram parte de suas vidas ao mundo dos livros, pois cremos ter ficado bastante claro que quando falavam de cultura, estavam falando também de literatura, e que quando falavam disso falavam igualmente de arte, de civilização, de nação e ainda de si mesmos. Mas o que se entendia então por cultura? E o que os livros representariam nesse contexto?

\section{Os Livros e a Terra da Cultura Intelectual}

Durante o percurso até aqui realizado, foram muitas as vezes que nos deparamos com a figura do livro. Na verdade, foi justamente essa ocorrência que terminou por conduzir - mesmo que indiretamente - os caminhos da nossa reflexão. A presença constante do livro, em todas as suas modalidades, e a própria importância que a ele se atribuía nesse contexto constituem por si só um grande problema histórico que merece certamente alguma atenção. Dentro de seus limites, a investigação aqui conduzida procurou privilegiar apenas alguns aspectos particulares desse problema. O livro de que viemos falando até aqui, nesse sentido, refere-se muito mais a um bem simbólico do que material. O que nos chamou a atenção, acima de tudo, foi a complexa trama de ideias e representações em que estaria então envolvido, bem como os códigos comportamentais 
próprios que engendrava. $\mathrm{O}$ acesso a esse universo, por sua vez, permitiu-nos realizar alguns apontamentos gerais no tocante ao sistema de apreciação de um grupo específico de pessoas. Delineamos, assim, os contornos do grande entusiasmo que circundava suas atividades, e esforcemo-nos por compreender como essas pessoas se representavam frente a si mesmas; indaguemo-nos ainda a respeito do que pensavam estar fazendo, e do que, afinal, significaria o conjunto de suas práticas. Deste modo, em termos do argumento e da estrutura geral do texto será interessante falar sobre o livro neste momento. Através deste recurso, tentaremos amarrar algumas das principais ideias que atravessam a pesquisa, demonstrando que, a nosso ver, ou elas se dão em função do livro, ou estão a ele profundamente atreladas.

A proximidade de sentido entre o que se designava por "cultural" e aquilo que se entendia por "literário" parece se constituir num indício importante na abordagem dos problemas aqui arrolados. Segundo essa constatação, dedicar-se à cultura era dedicar-se sobretudo às lides literárias, ou, como era igualmente frequente, às "lides do espírito". A palavra impressa, portanto, desfrutava nesse momento de um prestígio muito grande em vários de seus aspectos e relações. Se considerarmos, por exemplo, que o perfil de cultura vislumbrado acima se vinculava também a ideais de nacionalismo e mesmo de civilização, isso fica bastante patente. O envolvimento com o impresso, nesses termos, ultrapassa em muito uma crítica demasiado materialista que acaba, como diz Pierre Bourdieu (apud CHARTIER, 1996, p.243), “por subestimar o poder específico do intelectual que é o poder simbólico, o poder de agir sobre as estruturas mentais e, através da estrutura mental, sobre as estruturas sociais".

Em certo sentido, esse poder se estende ou se dá por meio do próprio livro. Embora não seja possível postular sua absoluta eficácia frente aos indivíduos, reduzida ou ampliada por uma série de outras determinações (editoriais, de leitura, etc.), é inegável que esse poder de fato existe. Mesmo que não saibamos em que exata medida a leitura estaria agregada à condução/compreensão da vida das pessoas cujas cartas trabalhamos, é razoável supor que fosse uma atividade frequente entre os membros de um grupo dedicado acima de tudo a incrementos no âmbito cultural. Se levarmos em conta que essa dedicação traduzia-se especialmente nas atividades ligadas à produção literária e ao universo da palavra impressa, de um modo geral a leitura constituiria então uma prática indissociável no viver diário da instituição. Sua própria lógica de funcionamento, que preconizava a circulação, difusão e produção de conhecimento, colocaria a leitura em posição de destaque frente às demais atividades.

Essa circulação, por sua vez, não se restringia apenas ao sistema de permuta entre agremiações e estabelecimentos. Ela se dava também entre os seus próprios membros, como deixa entrever a carta do poeta Leonardo Henke a Ribas da Silveira. Em fevereiro de 1950, de Curitiba, ele escrevia o seguinte: 
O segundo exemplar, dos que tive a honra de receber de V. S., do seu portentoso e sublime poêma épico "Destruição de Jerusalém por Tito", e que eu destino ao ilustre intelectual Dr. Sotero Angelo, foi-me arrebatado, frenéticamente, das mãos pelo Dr. Dálio Zippin. Êste, a quem eu cedera o livro, por momentos, e após lêr, de salto, algumas estrofes, só prometeu devolver-me o livro, afim de eu poder entregalo ao Dr. Sotero, depois de lê-lo inteiro e aprecia-lo da primeira à ultima estância, tendo-me prometido, escrever uma apreciação, que faremos publicar brevemente, e tão logo me seja entregue, pelo Sr. Dálio, o qual asseverou-me, que não tardaria em devolver-me a óbra, juntamente com um seu escrito, sobre a mesma. Poderá, assim, V. S. contar com 3 publicações, no mínimo, exaltando êsse primoroso poema de sua lavra, que tanto nobilita ao Paraná, e cuja divulgação, por isso mesmo, se torna dever. $^{33}$

Além da questão da troca e circulação constante de livros, os episódios narrados por Leonardo Henke apresentam-nos ainda uma outra prática comum no âmbito intelectual: a elaboração e a publicação de apreciações de leitura. Esse expediente também deveria estar investido de grande importância naquele contexto, na medida em que colocava em jogo uma série de elementos como reconhecimento, influência e prestígio, determinantes em grande parte do capital e da proeminência social desfrutado tanto dentro como fora do grupo. O poder simbólico engendrado no interior dessas práticas, portanto, age também por extensão sobre a própria estrutura da sociedade, seja através dos jornais, das emissoras de rádio, das conferências e palestras, etc.

Uma outra maneira de se constatar o alcance desse intrincado jogo de influências é observar o modo como a leitura extrapolava o campo circunscrito dos intelectuais. Após contar-nos um pouco da aventura do livro de Ribas da Silveira, bem como das impressões que viriam logo mais respaldálo e creditá-lo, Henke revelava em seguida: "Pessoas de minha família, a quem tive oportunidade de lêr as fulgurantes estâncias de sua lavra, ficaram encantadas, com a força e a beleza poética de seu estro, compartilhando comigo, suas emoções". ${ }^{34}$ Aos historiadores preocupados com as diferentes modalidades da leitura no passado, tal testemunho poderia suscitar inúmeras questões. Eles poderiam perguntar-se, por exemplo, se esse tipo de leitura coletiva ou em família constituiria uma prática comum naquele contexto ou se seria apenas o contorno de uma forma específica de leitura ligada aos textos religiosos. Embora não possamos responder de momento a essas questões, podemos continuar acompanhando as palavras de Henke e perscrutar algo mais sobre sua leitura. Em tom emotivo, ele prosseguia:

"Destruição de Jerusalém por Tito", possue todos os predicados para tornar-se obra imortal: A verdade histórica da mais sublime das histórias; virtuosidade inexedivel [sic]; estilo claro, conciso e brilhante; pureza de linguagem e uma simplicidade e perfeita adaptação das descrições às causas e passagens, que se vão sucedendo, em seqüência dinâmica, natural e fluente, empolgando ao leitor extasiado, dando, às vezes, a impressão de estarmos ante uma das mais portentosas creações do espírito humano, outras vezes, facinando-nos [sic], a ponto, de nos sentirmos enquadrados, ao tema, vivendo com os personagens bíblicos, os dramas do cristianismo, 
descritos de maneira magistral, no poema que mereceu, justamente, da Academia Brasileira de Letras, menção honrosa. ${ }^{35}$

Ao expor suas impressões de leitura, Leonardo Henke acaba tocando em um outro ponto muito importante: o livro a que se refere estaria, segundo o que nos diz, entre as "mais portentosas criações do espírito humano". Esse tipo de associação, que entende ou situa o labor intelectual e literário no plano espiritual, apareceu de forma indireta em cartas citadas anteriormente e marca indelevelmente um número significativo de correspondências. Entre essas, a carta do advogado Serafim França, datada de 10 de setembro de 1951 e endereçada ao então primeiro secretário do CCEC, Cyro Ehlke, apresenta um conteúdo particularmente interessante e pode nos ajudar a pensar essa questão. A exemplo de muitos, ele começava comentando a respeito de sua admissão:

Sensibilizou-me profundamente o gesto honroso desse Centro e dele muito me envaideço de pertencer, contribuindo com tudo o que estiver ao meu alcance para a realisação [sic] de suas magníficas finalidades.

Somente as obras do espírito poderão nos assegurar uma vida melhor, no mundo de confusão em que vivemos.

Poucos são os homens que olham para o céu. Trava-se em toda a parte uma luta de egoísmo inferior, de visão terra a terra, destruindo as virtudes e embargando os caminhos de felicidade.

Invade-nos um materialismo grosseiro, destruidor de nossos princípios de civilisação [sic].

Temos que congregar as forças imunes, num idealismo construtivo.

A reação do espírito é como a dos raios luminosos no seio da treva.

Temos altos guias para a cruzada redentora.

O pensamento tem mais poder do que a espada.

É nobre a missão dos batalhadores da luz, contra os inimigos da sombra.

Havemos de afirmar a nossa pátria com a inspiração colhida nas palpitações de sua grandeza e não com o negativismo intruso que nos rebaixa e destrói.

Temos que estudar e sonhar, criar asas e não patas de chumbo.

Cada Centro Cultural é uma torre de sonho e defesa.

Não importa que sejam poucas as legiões dessa peleja. A causa é a da verdade sagrada, que tem energia invencível.

Havemos de pôr sól no cáos. Contribuiremos, ao menos, com uma centelha. Replantaremos as seáras devastadas por Átila [...].

Vamos trabalhar pela espiritualidade, em sua latitude mais pura.

Eu sou um obreiro modesto, mas deligente [sic]. Farei o que puder. ${ }^{36}$

Esta carta reúne praticamente todos os elementos que viemos discutindo até aqui. Para aquele que a escreveu - como para João Pereira em carta acima citada -, os "caminhos de felicidade" também passariam pela negação do "egoísmo inferior": concorrer para a grandeza da pátria, portanto, implicaria abdicar aos vícios do individualismo, ao "materialismo grosseiro" e destruidor das virtudes, "congregando as forças imunes num idealismo construtivo". Esse tipo de raciocínio, que privilegia a oposição direta entre duas ideias ou posturas distintas, perpassa integralmente o discurso de Serafim França. Observando-o com mais atenção, percebemos que os termos se distribuem nitidamente entre dois extremos antagônicos: o do "bem" (idealismo, espiritualidade, 
luz, sol, etc.), e o do "mal" (materialismo, egoísmo, treva, caos, etc.). A oposição entre esses extremos, no entanto, é associada a um cenário de conflito iminente ou imediato cuja causa é unicamente a da "verdade sagrada". Verticalmente, o embate se exprimia da seguinte forma: sonhos e imaginação contra a mesquinharia da "visão terra a terra"; "asas" contra o enraizamento e imobilidade das "patas de chumbo".

É difícil deixar de notar o teor religioso de algumas convicções endossadas por Serafim França em sua carta. O conflito que ele aponta, por exemplo, se traduz nos termos de uma "cruzada redentora" (sob a bandeira da "verdade sagrada") contra os "inimigos" oriundos das "sombras". O idealismo que insiste em defender, por sua vez, tem algo a ver com voltar ou não os olhos para o céu. A esse respeito, e não por acaso, o mesmo Agnello Bittencourt mencionado anteriormente escrevera em 1952: “Certamente, Ponta Grossa, na agitação do seu desenvolvimento, não cogitou de mais uma casa de diversões, porque suas vistas se voltaram para um ponto mais alto, sendo, então, criado o Centro Cultural "Euclides da Cunha". ${ }^{37}$ Ainda que não tenhamos condições de aprofundar aqui a análise nesse sentido, esse teor religioso reforça nossas conclusões sobre o emaranhado de ideias que enredava o grupo. Assim, se aquilo que se designava por "cultural" estava de fato muito próximo do que se tinha por "literário", esse último se dava sobretudo no domínio da espiritualidade. O livro, portanto, como obra do espírito, como bem cultural e simbólico, como produto e fruto do trabalho intelectual, seria um meio privilegiado para se reconstituir e se replantar as "searas" outrora "devastadas". Em outras palavras, era precisamente através dele que seria elevado à plenitude o conjunto das realizações individuais e coletivas, isto é, nacionais.

Esse raciocínio, por extensão, leva-nos novamente à questão do trabalho. A construção e sustentação da imagem do trabalhador, como dissemos, estariam ligadas a uma ideia de cultura bastante original. Já falamos algumas vezes que o papel do intelectual comprometia-se em muito com noções de patriotismo, de arte, de civilização e de ciência. Da mesma forma, foi possível observar que o sentido do termo cultura repousava no encontro de várias outras esferas como a literária, a espiritual, etc. Mas em quê, afinal de contas, consistiria essa ideia de cultura? Como ela era pensada naquele momento?

Em primeiro lugar, as pistas de que dispomos apontam para o fato de que a cultura era então pensada como um problema, como algo que demandaria atenção e dedicação. O cenário de conflito esboçado por França, nesse sentido, aparece justificado já em 1949, quando Lázaro de Campos assegurava sua colaboração "na [...] luta insana e frutífera em pról 'da Cultura e da dignificação do Saber' [...]". ${ }^{38}$ Mas este diagnóstico da cultura como problema, e desse mesmo problema como batalha, não encerra ainda nossa discussão. A ideia de cultura, na verdade, também tinha outras 
facetas. Em 11 de fevereiro de 1949, Raul Gomes começava em tom de concordância com os demais colegas:

Si problema existe no Paraná merecedor de cuidados diurnos e noturnos é o do incremento da nossa cultura

Pois esta não é palavra vã. O grande Littré define-a assim: "trabalho da terra, conjunto de operações próprias a obter do solo os vegetais de que o homem e os animais domésticos precisam".

Noutro parágrafo, o magnífico dicionarista dá-nos o sentido figurado do termo: "A cultura das letras, das ciências, das belas artes". E abona esse sentido com um passo de Cícero, tirado de seu discurso em defesa de Archias: "O pouco de conhecimento que possuo, devo-o à cultura das boas letras".

$\mathrm{Na}$ sua versão reta, portanto, cultura significa o rude trato do solo, assistência às suas faltas, solicitude permanente às plantas. ${ }^{39}$

A partir da definição do famoso dicionarista, Raul Gomes desenvolve uma concepção de cultura no mínimo curiosa. Embora o argumento por ele utilizado esteja absolutamente correto do ponto de vista etimológico, é preciso reconhecer, afinal, que quando pensamos hoje em "cultura" não mais pensamos ou dificilmente pensamos em algo como "solicitude permanente às plantas", pois atualmente estamos inclinados a compreendê-la em chave antropológica. Por outro lado, também é necessário admitir que, munidos de tal metáfora, "replantar searas devastadas" faz muito mais sentido. A compreensão de cultura como o cultivo daquilo que seria necessário e benéfico aos homens, desse modo, nos permite entender melhor a questão do incremento: assim como a terra, a cultura também demandaria assistência permanente às suas faltas. Além disso, a cultura que esses intelectuais tanto apregoavam e exaltavam em seus discursos parecia se tratar mesmo de um estado de espírito: ao serem conclamados a trabalhar pelo engrandecimento cultural do país, os intelectuais, os diletantes e entusiastas estariam, na verdade, promovendo simultaneamente o cultivo de si mesmos.

Mas e o livro? O que ele representaria junto a esse inusitado sistema de representações? Raul Gomes parece ter ainda algo a nos dizer nesse sentido. Dando continuidade às ideias desenvolvidas acima, ele argumentava:

Ora, a terra da cultura intelectual ou artística é a biblioteca. E esta infelizmente não na possuímos, pois as existentes portadoras de tal denominação não passam de coleções de livros.

Não contamos ainda com uma verdadeira conciencia [sic] cultural, não tendo podido ainda no-la fornecer a presença de muitos casos de esforços individuais, notáveis e honrosos para nossa terra.

[...] Isso não obstante nossas 14 e na iminência de 16 faculdades superiores! Bosquejei aí o nosso problema. Assim todo surto de núcleos dotados de programa específico de trabalhar pela nossa cultura deve merecer o apoio da intelectualidade. Cogita-se de obra essencial e urgente e indispensável. Daí o mérito do C. C. Euclides da Cunha. Chamado a cooperar convosco, ponho a insignificância de meus préstimos a vosso dispor. ${ }^{40}$ 
Em certo sentido, o discurso de Raul Gomes vem apenas reforçar o que já afirmamos antes sobre as funções da palavra impressa naquele contexto. Trabalhar no incremento da cultura, segundo o que ele nos diz, seria trabalhar também e, sobretudo, na ampliação e refinamento das bibliotecas. Assim, se no interior das mais candentes preocupações intelectuais, o livro, em particular, e a palavra impressa, em geral, sempre desfrutaram de uma posição bastante privilegiada, na metade do século passado essa situação parecia ter sido ainda pouco alterada: a concretização dos ideais de instituições como o CCEC passava necessariamente pela constituição e arregimentação de bibliotecas. Não obstante, o próprio processo de intercâmbio preconizado por essas instituições já acabava distinguindo duplamente o estatuto do escrito: por um lado, esse processo se dava em grande parte através de cartas; por outro, se concretizava, em grande parte, através de livros, jornais e revistas científicas. Nesse sentido, quando Raul Gomes afirma ser a biblioteca "a terra da cultura intelectual ou artística", não só vemos se mostrar mais uma vez a já comentada debilidade das fronteiras conceituais, mas visualizamos também a importância e a centralidade ocupada pelo livro no sistema de representações até aqui investigado.

No entanto, se trabalhar pelo aprimoramento cultural significava dedicar boa parte do empenho humano em trocar, reunir e escrever textos e livros, o envolvimento nesse universo parecia transgredir as paredes e as páginas de qualquer biblioteca. As agremiações de intelectuais, nesse sentido, demonstrariam preocupações notadamente amplas: "Compreendo que Centros como o "Euclides da Cunha”", escrevia Agnello Bittencourt, "muito concorrem para solidificar a unidade nacional em qualquer dos seus aspectos". Não podemos nos esquecer, contudo, que estes centros eram nada mais do que as pessoas que o constituíam e que também o inventaram. Sabendo disso, Bittencourt ainda acrescentava mais algumas palavras sobre aqueles os quais também pertenciam ao mesmo grupo dele:

Trocando pensamentos e entendendo-se, mesmo de pontos muito distantes, os homens de boa vontade podem irmanar-se, melhor do que agora, e criar um tipo de civilização que mais lhes convenha. Cada agrupamento que se funda e trabalha com essa finalidade, é uma sentinela avançada do nosso progresso, um broquel de paz e de segurança na eternização brilhante do nome do Brasil. Não há soberania nacional que dispense o apoio de seus intelectuais. A nação que os relegar a plano inferior, não estimando o seu auxílio, não passará de um bando de Panúrgio, que os espertos tanto conduzirão para o aprisco como para o matadouro. As cidades recomendam-os [sic] e glorificam-se com a manutenção carinhosa de suas escolas e centros culturais. ${ }^{41}$

Os intelectuais, para Agnello Bittencourt e outros, estariam estreitamente comprometidos com a solidificação da unidade nacional em qualquer dos seus aspectos. Como pudemos observar em ocasiões anteriores, a questão da coletividade em detrimento do individual é realmente muito forte 
nas correspondências. O fato desse argumento aparecer repetidas vezes travestido de injunções nacionalistas, é também um claro indício da presença de um elemento político no emaranhado de ideias aqui examinado. Embora esse seja outro dos vários problemas que ultrapassam nossas preocupações imediatas, é interessante e mesmo desejável investigá-lo melhor no futuro. De momento, é possível tomá-lo apenas como mais um sinal da extensão com que se apresentava então o campo de ação e influência do intelectual.

A maneira como esse grupo de intelectuais conjugava todas essas ideias não era um caso isolado. No começo do nosso percurso, havíamos comentado que a existência e a propagação de centros culturais e literários - essas "sentinelas avançadas do progresso", essas "torres de sonho e defesa" - poderia mesmo configurar um tipo de tendência comum à época. A nosso ver, a contiguidade existente entre esses diferentes estabelecimentos residiria justamente no modo como seus idealizadores se enxergavam frente à sociedade: na qualidade de letrados polivalentes, detentores e produtores do saber, na sua condição mesma de escritores esclarecidos, muitos desses indivíduos viam-se como peças importantes no engrandecimento cultural do país. Ao que parece, a principal justificativa para essas ideias encontrava-se na própria definição do que se designava por "cultural" naquele contexto: qualquer coisa de muito próximo ou que se dava principalmente na esfera literária ou intelectual.

Se forem válidas essas proposições, o pretendido engrandecimento cultural do país daria-se, sobretudo, por meio da palavra impressa. Não obstante, as próprias práticas de leitura e escrita já seriam alvos de uma dupla distinção no interior da lógica funcional desses grupos, que tinham na produção de textos e no intercâmbio de ideias suas principais atividades. A difusão do saber via palavra impressa, portanto, parecia ainda muito próxima dos termos em que era pensada no século XIX, "quando bibliotecas, imprensa, livros e escolas aparecem como espaços de realização futura da utopia do progresso, ao mesmo tempo que são os instrumentos de construção do caminho civilizacional que se imaginava para a nação" (DENIPOTI, 2004, p.151).

Assim, e pensando em termos de uma possível continuidade histórica, encerramos por aqui nossa breve incursão pelo mundo desses intelectuais. Ainda que muitas das proposições e hipóteses aqui esboçadas mereçam, sem dúvida, um tratamento isolado e mais atencioso, não devemos ignorar por completo tudo aquilo que pudemos apurar.

\section{Referências Bibliográficas}

CHARTIER, R. A leitura: uma prática cultural. Debate entre Pierre Bourdieu e Roger Chartier. In: . Práticas da leitura. São Paulo: Estação Liberdade, 1996, p. 229-253. 
. A ordem do livros: leitores, autores e bibliotecas na Europa entre os séculos XIV e XVIII. Brasília: Universidade de Brasília, 1999.

- O mundo como representação. In: - À beira da falésia. Porto Alegre: Ed. Universidade/UFRES, 2002, p. 61-79.

CORBIN, A. O território do vazio: a praia e o imaginário ocidental. São Paulo: Companhia das Letras, 1989.

DARNTON, R. O grande massacre de gatos e outros episódios da história cultural francesa. Rio de Janeiro: Graal, 1986.

DENIPOTI, C. Templos do progresso: instituições de leitura no Brasil oitocentista. In: PIERONI, G. (orgs.). Saberes brasileiros: ensaios sobre identidades: séculos XVI a XX. Rio de Janeiro: Bertrand Brasil, 2004, p. 143-162.

. Um homem no mundo do livro e da leitura. Revista de História Regional, Ponta Grossa: UEPG, vol. 6, n. 2, p. 75-91, inverno 2001.

DITZEL, C. de H. M. O arraial do Pitangui: o Centro Cultural Euclides da Cunha de Ponta Grossa. In: __ ; SAHR, Cicilian Luiza Löwen (orgs.). Espaço e Cultura: Ponta Grossa e os Campos Gerais. Ponta Grossa: UEPG, 2001, p. 211-227.

. O arraial e o fogo da cultura: os euclidianos pontagrossenses. 1998. Dissertação (Mestrado em Educação) - Universidade Estadual de Ponta Grossa, Ponta Grossa, 1998.

GINZBURG, C. O queijo e os vermes: o cotidiano e as idéias de um moleiro perseguido pela Inquisição. São Paulo: Companhia das Letras, 1987.

GOMES, J. M. L. de O. Instrumento de Pesquisa para a História Local. Monografia (Especialização em História do Paraná) - Universidade Estadual de Ponta Grossa, Ponta Grossa, 1997.

; SACCHELLI, M. J. Laboratório de Pesquisa em História - Universidade Estadual de Ponta Grossa. In: ENCONTRO REGIONAL DE HISTÓRIA: VIOLÊNCIA E DIRETIOS: 500 ANOS DE LUTAS, 7., 2001, Londrina. Anais... Curitiba: Aos Quatro Ventos, 2001. p. 109-116.

OLIVEIRA, J. C. de. Educadores Ponta-grossenses: 1850-1950. Ponta Grossa: Editora UEPG, 2002.

ROSE, J. The horizon of a new discipline: inventing book studies. Publishing Research Quaterly. Piscataway New Jersey, p. 11-19, Spring, 2003.

SCHWARCZ, L M. O espetáculo das raças: cientistas, instituições e questão racial no Brasil 1870-1930. São Paulo: Companhia das Letras, 1995.

VEYNE, P. Como se escreve a história. Lisboa: Edições 70, 1987.

WANKE, E. T. Faris Michaele, o tapejara: uma biografia. Rio de Janeiro: Edições Plaquette, 1999. 


\section{NOTAS}

${ }^{1}$ Este trabalho está vinculado ao Centro de Estudos em História da Leitura, do Livro e da Biblioteca (CEHBIB), do Departamento de História da Universidade Estadual de Ponta Grossa.

${ }^{2}$ Carta de Augusto Faria Rocha a Cyro Ehlke, secretário do CCEC. Antonina, 5 de setembro de 1949.

${ }^{3}$ Entre 1960 e 1980 há 43 cartas recebidas. Optamos então por excluí-las da análise, dada sua rarefação e descontinuidade.

${ }^{4}$ Doada em 1995 ao Departamento de História da Universidade Estadual de Ponta Grossa, a documentação do Centro Cultural Euclides da Cunha apresenta um acervo com cerca de 5.000 livros, 345 títulos de revistas, além de um grande número de cartas enviadas por intelectuais do Brasil e do exterior como Gilberto Freyre, Érico Veríssimo, Roquete Pinto, Cândido Rondon, Luís da Câmara Cascudo, Roger Bastide, Valfrido Pilotto, Raul Gomes, entre outros. Também fazem parte deste acervo alguns recortes de jornais, somados a outros manuscritos, discursos e periódicos literários como o jornal Tapejara, editado pelo próprio Centro no período de 1950-1976 (GOMES; SACCHELLI, 2001, p.109$116)$.

${ }^{5}$ Trata-se do já mencionado CEHBIB. Além do presente artigo, algumas recentes investidas do CEHBIB podem ser encontradas em: BARUFI, C. A. Espaço feminino e práticas de leituras femininas no Centro Cultural Euclides da Cunha. Monografia (Graduação em História) - Universidade Estadual de Ponta Grossa, Ponta Grossa, 2006; DENIPOTI, C.; GONZATTO, C. Horizontes de expectativas: leitores e continuadores de Euclides da Cunha nas páginas do jornal Tapejara em Ponta Grossa, 1952. In: Revista de História Regional, Ponta Grossa, vol. 12, n. 2, p.6592, Inverno, 2007; PINTO, L. C. O livro como dádiva: as dedicatórias manuscritas dos livros do Centro Cultural Euclides da Cunha de Ponta Grossa - 1950-1960. Monografia (Graduação em História) - Universidade Estadual de Ponta Grossa, Ponta Grossa, 2006.

${ }^{6}$ Nascido em 3 de setembro de 1911, Faris Antônio Salomão Michaele é natural de Mococa, interior do Estado de São Paulo. Filho de imigrantes da região de Akar, extremo norte do Líbano, Faris mudou-se com a família de Mococa para Ponta Grossa em 1913 ou 1914, e em 1936 formou-se bacharel em Direito pela Faculdade de Direito do Paraná. Os interesses de Faris, contudo, iam desde a filosofia até a linguística, desde a etnologia até a literatura, como deixam entrever, por exemplo, os títulos de algumas de suas obras: Ensaios contemporâneos (1940), Titãs de bronze (1943), Manual de conversação da língua tupi (1951), Breve introdução à antropologia fisica (1961), Arabismos entre os africanos da Bahia (1968), entre outras. Faris foi membro de diversas instituições culturais e literárias nacionais e internacionais, e esteve profundamente envolvido no processo de instalação da Faculdade de Filosofia Ciências e Letras da cidade de Ponta Grossa. Além disso, Faris foi também responsável pela fundação de várias entidades na cidade como o Grêmio Literário Visconde de Taunay, o Centro Cultural Inter-Americano, o Museu Campos Gerais e o próprio Centro Cultural Euclides da Cunha, do qual foi também presidente até 1977, ano de seu falecimento. Para saber mais sobre Faris Michaele consultar os trabalhos de Eno Theodoro Wanke (1999) e Joselfredo Cercal de Oliveira (2002, p.109-111).

${ }^{7}$ Paul Veyne (1987, p.198) define a seriação como "método que consiste em recolher, para interpretar um facto, o maior número possível de ocorrências desse facto: recolher todos os empregos duma palavra dada nos textos conservados, ou todos os exemplos dum costume".

${ }^{8}$ Carta de Durval Borges endereçada ao Centro Cultural Euclides da Cunha. Curitiba, 27 de outubro de 1948.

${ }^{9}$ Carta de remetente desconhecido [assinatura ilegível] endereçada ao Sr. Presidente do CCEC. Rio de Janeiro, 12 de fevereiro de 1949.

${ }^{10}$ Carta de Alcântara Nogueira a Faris Michaele, presidente do CCEC. Rio de Janeiro, 10 de março de 1949.

${ }^{11}$ Carta de J. de Souza Ferreira a Faris Michaele, presidente do CCEC. Curitiba, 5 de abril de 1950.

${ }^{12}$ Carta de Silvino A. Sanders dirigida ao CCEC. Ponta Grossa, 30 de outubro de 1950.

${ }^{13}$ Carta de João Pereira a Faris Michaele, presidente do CCEC. Rio de Janeiro, 18 de junho de 1949.

${ }^{14}$ Idem.

${ }^{15}$ Carta de Adar de Oliveira e Silva à Diretoria do CCEC. Ponta Grossa, 5 de maio de 1951.

${ }^{16}$ Carta de Augusto Faria Rocha a Cyro Ehlke, secretário do CCEC. Antonina, 5 de setembro de 1949.

${ }^{17}$ Idem.

${ }^{18}$ Carta de Raimundo M. Ayres a Faris Michaele, presidente do CCEC. Guiratinga, 22 de junho de 1949.

${ }^{19}$ Idem.

${ }^{20}$ Carta de Raimundo M. Ayres a Faris Michaele, presidente do CCEC. Guiratinga, 25 de janeiro de 1954.

${ }^{21}$ Carta de Nilo Brandão ao secretário do CCEC. Curitiba, 12 de abril de 1950.

${ }^{22}$ Carta de Alcyone Moraes Vellozo a Cyro Ehlke, secretário do CCEC. Curitiba, 3 de outubro de 1951.

${ }^{23}$ Carta de Heloísa A. Tôrres a Cyro Ehlke, primeiro secretário do CCEC. Rio de Janeiro, 23 de janeiro de 1952.

${ }^{24}$ Carta de Agnello Bittencourt a Cyro Ehlke, primeiro secretário do CCEC. Rio de Janeiro, 18 de agosto de 1952.

${ }^{25}$ Carta de Felizardo Gomes da Costa à diretoria do CCEC. Curitiba, 1 de novembro de 1949.

${ }^{26}$ Carta de Paulino Santiago ao primeiro secretário do CCEC. Maceió, 17 de setembro de 1951.

${ }^{27}$ Carta de Manoel de O. Franco Sobrinho à diretoria do CCEC. Curitiba, 20 de outubro de 1949.

${ }^{28}$ Carta de Durval Borges ao CCEC. Curitiba, 5 de março de 1949.

${ }^{29}$ Carta de Newton Souza e Silva a Faris Michaele, presidente do CCEC. Ponta Grossa, 29 de maio de 1950.

${ }^{30}$ Carta de Felizardo Gomes da Costa à diretoria do CCEC. Curitiba, 1 de novembro de 1949. 
${ }^{31}$ Carta de Gabriel Pinto Assunção ao CCEC. 20 de janeiro de 1954.

${ }^{32}$ Carta de Plínio Ayrosa a Cyro Ehlke, secretário do CCEC. São Paulo, 8 de março de 1949.

${ }^{33}$ Carta de Leonardo Henke a Ribas da Silveira. Curitiba, 5 de fevereiro de 1950.

${ }^{34}$ Idem.

${ }^{35} \mathrm{Idem}$.

${ }^{36}$ Carta de Serafim França a Cyro Ehlke, primeiro secretário do CCEC. Curitiba, 10 de setembro de 1951.

${ }^{37}$ Carta de Agnello. Bittencourt a Cyro Ehlke, primeiro secretário de CCEC. Rio de Janeiro, 18 de agosto de 1952.

${ }^{38}$ Carta de Lázaro Nini de Campos a Faris Michaele, presidente do CCEC. Ponta Grossa, 16 de abril de 1949.

${ }^{39}$ Carta de Raul Gomes ao CCEC. Curitiba, 11 de fevereiro de 1949.

${ }^{40}$ Idem.

${ }^{41}$ Carta de Agnello. Bittencourt a Cyro Ehlke, primeiro secretário de CCEC. Rio de Janeiro, 18 de agosto de 1952.

Artigo recebido em 01/2010. Aprovado em 03/2010. 